\title{
Las alquerías del valle de Lecrín: notas sobre su poblamiento y urbanismo
}

\author{
María Aurora Molina Fajardo | Universidad de Granada \\ URL de la contribución <www.iaph.es/revistaph/index.php/revistaph/article/view/3895>
}

\section{RESUMEN}

En el siguiente texto se presenta una sucinta introducción al poblamiento y estructura urbana de las localidades del valle de Lecrín durante los últimos años del siglo XV y el XVI. Se considera para ello el origen histórico de estos asentamientos señalando la organización medieval de la comarca a través de alquerías.

De igual modo, se analiza brevemente la configuración espacial de aquellos asentamientos distribuidos en barrios más o menos independientes; y se enumeran algunos de sus hitos arquitectónicos y espaciales más significativos desde el punto de vista poblacional: su entramado viario, sus espacios religiosos, defensivos, públicos, domésticos, industriales, destinados a la explotación del medio circundante, etc.

\section{Palabras clave}

Al-Andalus | Alquerías | Arquitectura agraria | Arquitectura defensiva | Arquitectura doméstica | Barrios | Granada (Provincia) | Mezquitas | Molinos | Poblamiento | Reino de Granada | Territorio | Urbanismo | Valle de Lecrín | 


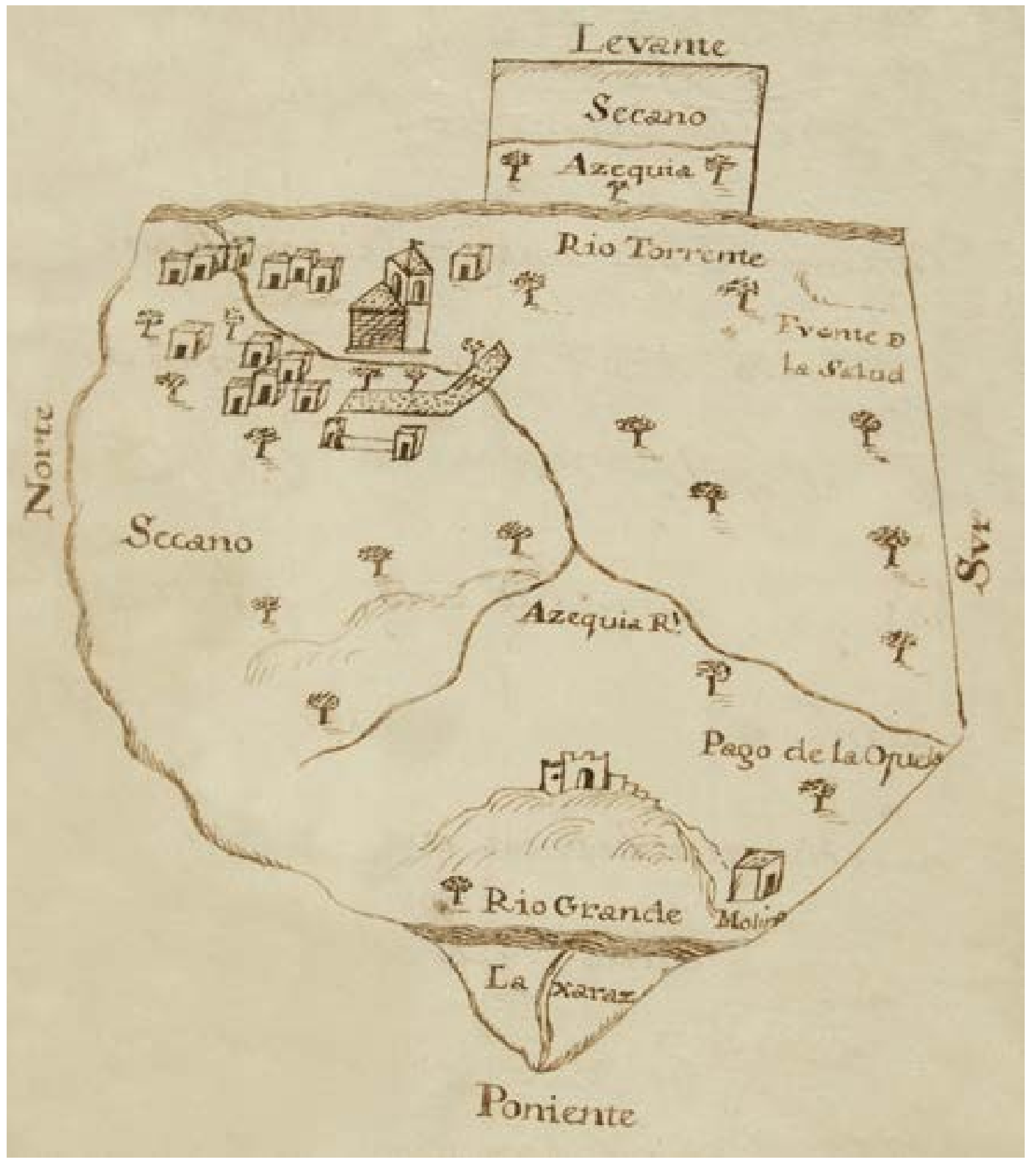

Dibujo del pueblo de Murchas y de la antigua alquería de Lojuela inserto en el Catastro del Marqués de Ensenada de Murchas. En este mapa del siglo XVIII se aprecia una clara organización espacial de casas agrupadas en manzanas más o menos regulares dentro del pueblo, destacando igualmente el entramado de acequias que abastecía de agua el caserío y fertilizaba sus tierras. Como eje también ordenador del territorio se dibujó el castillo del despoblado de Lojuela | fuente Archivo Histórico Provincial de Granada. Hacienda. Catastro de Ensenada. Murchas, Libro 1431 
1

Alguna bibliografía al respecto: TORO MO YANO; ALMOHALLA GALLEGO, 1979: 1-20; GARCÍA GRANADOS et ál., 1983: 897-902; RAMOS MILLÁN; OSUNA VARGAS, 2001.

2

Los datos sobre los asentamientos de altura comarcales son realmente muy escasos; si bien existen detalles que quizás nos puedan hacer pensar que los yacimientos del Pago del Castillejo de Nigüelas y el del Cerro Alto de Acequias respondan a este tipo de ocupación del territorio. Más información en MOLINA FAJARDO, 2012: 981-989.

\section{INTRODUCCIÓN}

Una de las características que ha definido el poblamiento del valle de Lecrín ha sido su posición geográfica central dentro del territorio granadino. La comarca se sitúa al sur de Sierra Nevada limitando con la vega, el litoral de la provincia, las Alpujarras y el Temple. Esta ubicación geográfica ha hecho del valle de Lecrín un continuo lugar de tránsito, un verdadero cruce de caminos que ha marcado de forma considerable su historicidad. Del mismo modo, sus particularidades físicas y los tres ríos que lo recorren (Dúrcal, Torrente y Santo) han favorecido un asentamiento humano continuo que se documenta desde época prehistórica hasta nuestros días ${ }^{1}$. Con todo, será el periodo medieval el que configure esta tierra como un grupo comarcal propiamente dicho, compuesto por una serie de localidades dedicadas principalmente a la explotación de su medio circundante.

En este artículo propongo un brevísimo recorrido por la ordenación urbana de las antiguas alquerías del valle de Lecrín, sobre todo en los años posteriores a la conquista del Reino. Esta cronología nos acerca a un valle que, en menos de cien años, vivió sucesivas contiendas, la expulsión de su población autóctona y la repoblación de sus lugares con cristianos viejos procedentes de otras tierras. Todos estos acontecimientos -que incluso conllevaron la destrucción total o parcial de algunos asentamientos- marcarán el devenir poblacional de una comarca que se debatió entre el mantenimiento de su arraigada tradición andalusí y las nuevas prácticas propias del orden establecido.

La metodología adoptada para elaborar este texto ha sido principalmente la consulta de fuentes primarias (documentación de bienes habices junto a los libros de población existentes), así como el análisis del parcelario local cotejado con numerosas visitas de campo.

\section{UN VALLE DE ALQUERÍAS}

Durante las ocho centurias del Islam peninsular, el valle de Lecrín vivió distintos modos de ocupación que evolucionaron desde primitivos escenarios de encastillamiento ${ }^{2}$, a una organización espacial jerárquica y urbana 


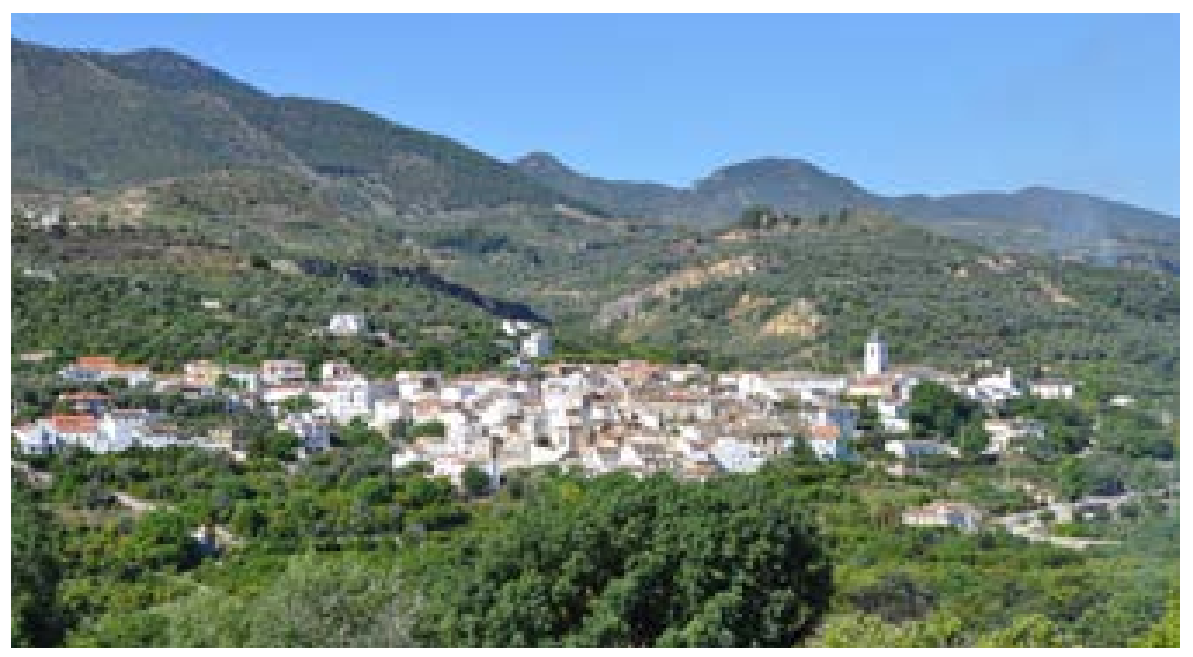

Vista del pueblo de Restábal desde Melegís | foto María Aurora Molina Fajardo, de todas las del artículo

que tendrá la alquería y su aparato defensivo como principales hitos ordenadores.

La historicidad del valle de Lecrín como ente comarcal parece retrotraerse a este periodo andalusí e incluso el topónimo Lecrín (del árabe Iqlīm, "clima" o "distrito") incide en esa agrupación fáctica de poblaciones de tiempos medievales.

En 1501, en la relación de los bienes habices de la Taha del Val de Aleclim se citan las siguientes localidades: Padul, Concha, Coxbixa, Durcal, Harat Alharab, Achit, Mondujar, Çeca, Leuxa, Exbor, Buñuelas, Lanjaron, Beznar, Tablate, Saleres, Restabal, Melexix y Molchas (Archivo General de Simancas

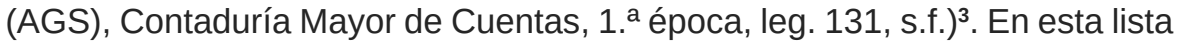
se obviaron los lugares de Nigüelas y Pinos del Valle que sí fueron incluidos junto a otros dos más -Naio y Cautil ${ }^{4}$ - en la Bula de Erección de las Iglesias del valle de Lecrín del mismo año (ESPINAR MORENO, 2009:35).

Así, el valle de Lecrín encontrado por los castellanos respondía territorialmente -a grandes rasgos- a la comarca actual ${ }^{5}$ y se caracterizaba por ser un distrito eminentemente aldeano, muy fortificado y dividido en alquerías de diversa consideración. Estos asentamientos, aunque autónomos, vivían bajo la influencia de la medina de Granada y tenían fuertes vínculos de vecindad compartiendo incluso parte de los recursos existentes en su medio. Aunque cada pueblo presenta singularidades propias, todos fueron ocupados por una sociedad islámica tribal que proyectó un mismo modo de poblar y explotar la zona. Me refiero: a la distribución de la alquería en barrios relativamente autónomos, a la importante presencia del aparato defensivo local así como a la organización de los lugares en relación al desarrollo y funcionamiento de sus sistemas hidráulicos ${ }^{6}$.
En la actualidad estas alquerías se reconocen con los nombres de: Padul, Cónchar, Cozvíjar, Dúrcal, Talará, Chite, Mondújar, Acequias, Lojuela, Ízbor, Albuñuelas, Lanjarón, Béznar, Tablate, Saleres, Restábal, Melegís y Murchas.

4

Los lugares de Naio -también referido como Najo- y Cautil -más conocido como Cantilse corresponden con dos de los barrios de la antigua alquería de Albuñuelas. Según su Libro de población creo poder situar el barrio de Najo como el vecindario donde se halla la torre del Tío Vayo. Por su parte, la localización del barrio del Cantil es más clara pues corresponde al sector bajo local, también citado en la documentación como barrio de Santiago y barrio de San Juan (FERRER, 2003: 105, 142, 186).

5

Hay que hacer notar que en nuestros días Lanjarón forma parte de la mancomunidad de municipios de La Alpujarra.

\section{6}

El diseño, organización e implementación de los conjuntos hidráulicos comarcales Ilevó consigo una importante planificación que condicionó incluso los emplazamientos físicos elegidos para el establecimiento del pueblo. Estos sistemas de regadío respondían a la necesidad de un flujo continuo de agua indispensable para el desarrollo de una nueva agricultura y requerían, asimismo, de unas estrategias socio-culturales determinadas para su mantenimiento y funcionalidad. Estos grupos hidráulicos están absolutamente ligados a la esfera no solo agrícola sino también urbana de los lugares del valle de Lecrín, siendo esta vinculación especialmente llamativa en algunas alquerías como Acequias. Más información sobre el desarrollo urbano de acequias y su sistema hidráulico en MOLINA FAJARDO, 2017: 266-275; 2012: 147-166. Un estudio para el conocimiento del regadío medieval de la zona norte del Valle de Lecrín es GARCíA PÉREZ, 2015. 


\section{7}

Vestigios de ese pasado clánico se descubren en la toponimia de algunos lugares. Un ejemplo es el nombre de Talará, uno de los principales núcleos de población del municipio de Lecrín. Este topónimo procede de árabe Harat al-`Arab y significa "barrio de árabes" (GARCÍA DEL MORAL, 2010: 658-664). Otro topónimo de clara ascendencia tribal se aprecia en el apeo de los bienes habices de la alquería de Acequias, realizado en 1502 Entre las propiedades anotadas se citan algunas en el Harat Ynbran que significaría "barrio de Ynbran" (MOLINA FAJARDO, 2012: 149). Este apellido se registra también en Restába en época morisca (1547) cuando se alude a un tal Alonso Ynbran durante el deslinde de los bienes pertenecientes a la Capellanía de Alconada de dicho pueblo (Archivo Histórico Diocesano de Granada (AHDGr), Libro Becerro de los Bienes Habices pertenecientes a las Iglesias del Valle de Lecrín, Caja n. ${ }^{\circ} 44$, fol. 99r.)

Este hecho parece claro en Padul cuando, el 5 de julio de 1571 el juez tomó posesión de las casas de moriscos que ya habían sido expulsados del pueblo. En esta enumeración se percibe claramente como distintas generaciones de un mismo grupo vivían en el mismo lugar; por ejemplo, la familia Zafra tenía tres hogares juntos: el de García, Baltasar y Martín de Zafra (FERRER, 1994: 82); o los Madara que moraban tres generaciones diferentes en el mismo sitio, Juan Madara el viejo, su hijo Hernando de Madara -entonces en galerasy, entre ambos, el vástago del anterior Alonso el Chapi (FERRER, 1994: 86, 87).

"El dicho lugar de Durcal esta dividido e apartado en seis varrios, que se llaman marjena, almohata alta, e baja, Celdelaque, e balma, e alauxa, e audarro, e no ai mas de una Yglesia donde se diga misa que esta acia el varrio principal, aunque en el de Márgena ai una hermita. Ai ansi mismo un varrio en el dicho lugar que pertenece a su Magestad" (Archivo His tórico Provincial de Granada (AHPGr), Libros de Población del Reino de Granada- 6678, fol. 9v.).
Las alquerías del valle de Lecrín se estructuraron a través de barrios con cierta autonomía y separados entre sí que, originalmente, debieron de ser fundados y poblados por una tribu concreta ${ }^{7}$. Esta génesis clánica progresivamente fue evolucionando hacia una sociedad vecinal. No obstante, la agrupación de familias más o menos amplias morando en un mismo espacio es algo que se documenta en la comarca incluso en las últimas décadas del siglo $\left.\mathrm{XV}\right|^{8}$. Los barrios se organizaban gracias a un caserío compacto que formaba manzanas de orden cerrado en las que se intercalaban huertos y corrales. Estas manzanas se separaban por calles casi siempre estrechas e irregulares. Sin embargo, solían existir una o dos vías principales de trazado regular que comunicaban los ámbitos domésticos con los espacios de uso comunitario, tales como el oratorio, la plaza o el mercado. El número de estos vecindarios fue diferente en cada alquería: hubo pueblos de mayor tamaño como Dúrcal -dividido en seis barrios aún hoy más o menos identificables ${ }^{9}$ - y otros de menor entidad como Ízbor, que solo tendría uno y se cita en su Libro de población como "un lugar pequeño"10.

Cada barrio contaba con sus propias infraestructuras y servicios llegando en ocasiones a ser tan autónomos que parecían más pequeñas alquerías anejas a otra superior. Un ejemplo es Pinos del Valle que, aunque contó con cuatro barrios ${ }^{11}$, dos de ellos -el alto y el bajo- resultaron tan principales y claramente diferenciados que se citaron como "alquería alta y baja" propiamente dicha ${ }^{12}$.

Un punto de inflexión importante para estos asentamientos fue la Guerra de las Alpujarras, la ruina que ocasionó, así como la posterior expulsión de sus habitantes moriscos. Gracias a los libros de población sabemos que alquerías como Acequias, Restábal o Tablate no conservaron ninguna casa habitable y otras como Lanjarón, Padul, Pinos del Valle o Talará quedaron muy afectadas (MOLINA FAJARDO, 2012: 269-272). Este panorama desolador y la llegada inestable de repobladores a la comarca propició un progresivo y -en ocasiones meditado- abandono de ciertos pueblos y barrios hoy convertidos en campos de cultivo (más información en MOLINA FAJARDO, 2012: 91, 142-143, 161-166, 170-173, 263-265). Así, tras la repoblación filipina comenzó una progresiva redistribución territorial del valle de Lecrín que redujo el espacio urbano andalusí previo ${ }^{13}$.

\section{EN LA ALQUERÍA Y SUS BORDES}

A grandes rasgos, los barrios y pueblos de la comarca contaron con ciertos elementos comunes o señeros: uno o varios centros religiosos, algún tipo de fuerte o defensa, espacios públicos o de sociabilización y el caserío donde la población residía. Las alquerías del valle de Lecrín, según se lee en las fuentes documentales, tuvieron generalmente más de un espa- 


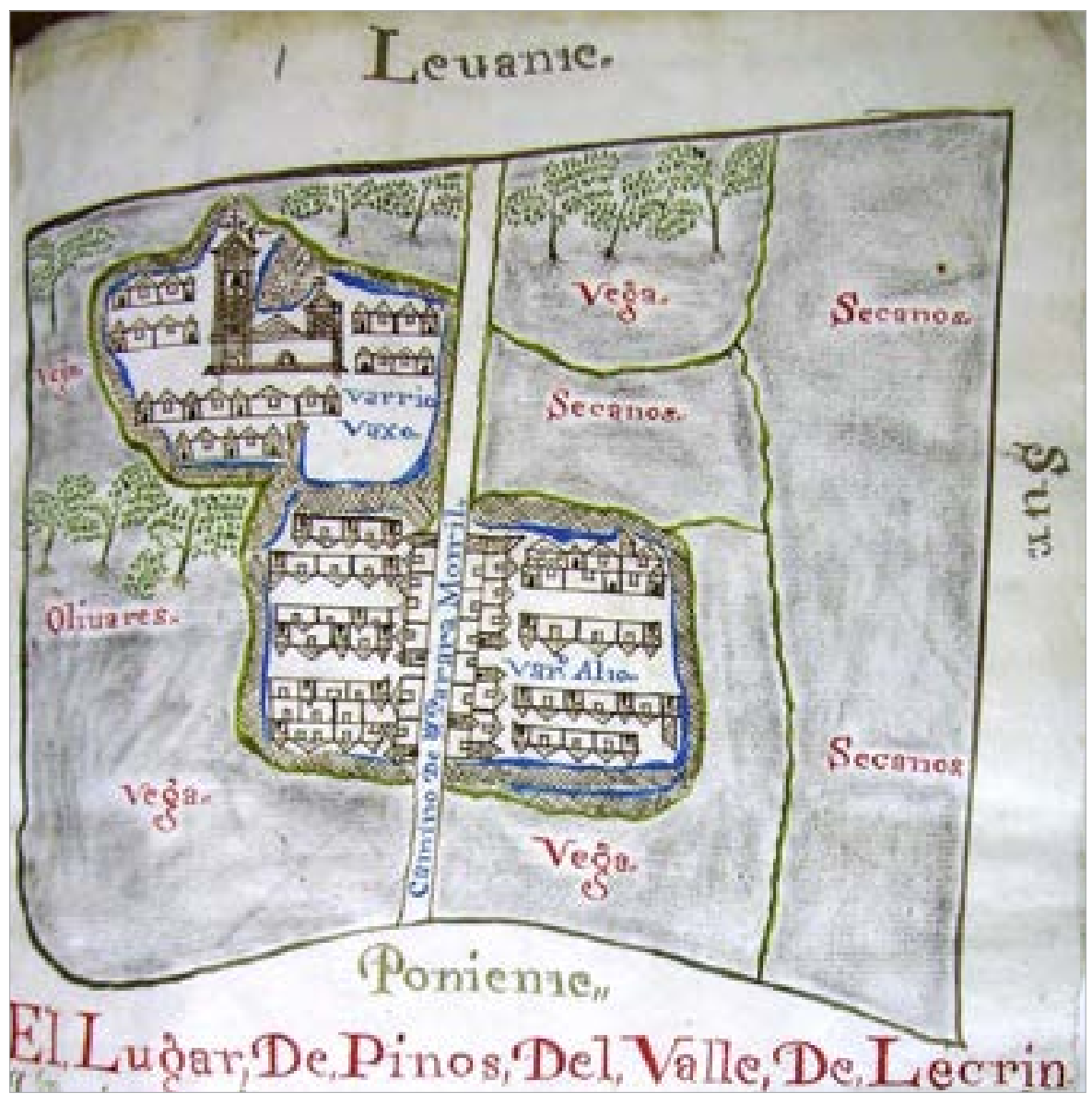

Dibujo de Pinos del Valle inserto en su Catastro del Marqués de Ensenada. En este croquis, incluso siendo de mediados del siglo XVIII, se aprecia esa clara distribución de la alquería en barrios | fuente Archivo Histórico Provincial de Granada. Hacienda. Catastro de Ensenada. Pinos del Valle, Libro 1494

cio religioso. Frecuentemente se distingue una mezquita principal con un cementerio cercano que congregaría al pueblo cada viernes; existiendo asimismo en cada barrio un oratorio menor o rábita que prestaría servicio a aquel vecindario. Estas rábitas fueron muy numerosas y parecen situarse principalmente en la entrada o salida de los pueblos pudiendo también tener algún tipo de necrópolis en sus inmediaciones. Otros dos elementos urbanos que se vincularon con los oratorios musulmanes fueron ciertos puntos hidráulicos relevantes para la comunidad (aljibes, fuentes, acequias, etc.) (MOLINA FAJARDO, 2017: 271-275) y los hornos de pan que solían ser propiedad de dichos templos. Con la conversión forzosa de los moriscos granadinos, muchas de estas mezquitas fueron transformadas en iglesias siendo luego destruidas para alzar el nuevo templo. Sin embargo, otras acogieron distintos usos (residencial, por ejemplo ${ }^{14}$ ) o fueron abandonadas. Una antigua mezquita de la que se ha conservado su alminar es la de Nigüelas. Ésta se ubicaba en el centro de los barrios locales, junto a un aljibe aún en pie.
10

AHPGr, Libros de Población del Reino de Granada-6724, fol. $26 \mathrm{v}$.

11

Más información sobre Pinos del Valle en MOLINA FAJARDO, 2012: 135-146.

12

"[...] camino que deciende de la Alqueria alta, é baja a la Alqueria baxa [...]" (AHPGr, Libros de población del Reino de Granada-6781, fols. $11 v, 12 r$.).

\section{3}

Los barrios que tras la repoblación filipina se despoblaron progresivamente fueron bastantes. Mientras algunos asentamientos como la alquería de Lojuela se encontraban en declive hacia 1572 -considerándose entonces un anejo de Murchas- otros ámbitos se repoblaron con normalidad. Éste fue el caso del barrio de Márgena, hoy principal vega de Dúrcal que, según he calculado contó con el 31\% de las residencias de todo el lugar (62 casas) de las que, actualmente no queda vestigio aparente. Pero si de un abandono urbano existe constancia por su intencionalidad, es el que vivió el barrio alto o del Cenete de Lanjarón. Este distrito fue el único que se mantuvo en pie tras la Guerra de las Alpujarras y, por esto, las autoridades repartieron allí las moradas a los pobladores. Si bien, a su vez les dotaron de solares en las partes bajas del pueblo obligándoles a que obraran nuevas casas y se mudaran con celeridad pues la ocupación del sitio no convenía para la "buena forma de la población” (FERRER, 2001: 166)

14

Un ejemplo de rábita que quedó incluida como parte de una casa fue la del barrio bajo de Béznar. Distinta documentación que versa sobre los bienes habices de esta localidad citan que Diego Borrique pagaba real y medio de censo cada año por una rábita que estaba dentro de la casa de Francisco de Escobedo, en su primer patio, y que tenía sembrados allí algunos limones (AHDGr, Libro Becerro de los Bienes Habices pertenecientes a las Iglesias del Valle de Lecrín, Caja n. ${ }^{\circ} 44$, fol. $205 r$ y en el mismo archivo, Signatura 585-F, fol. 2v.) 

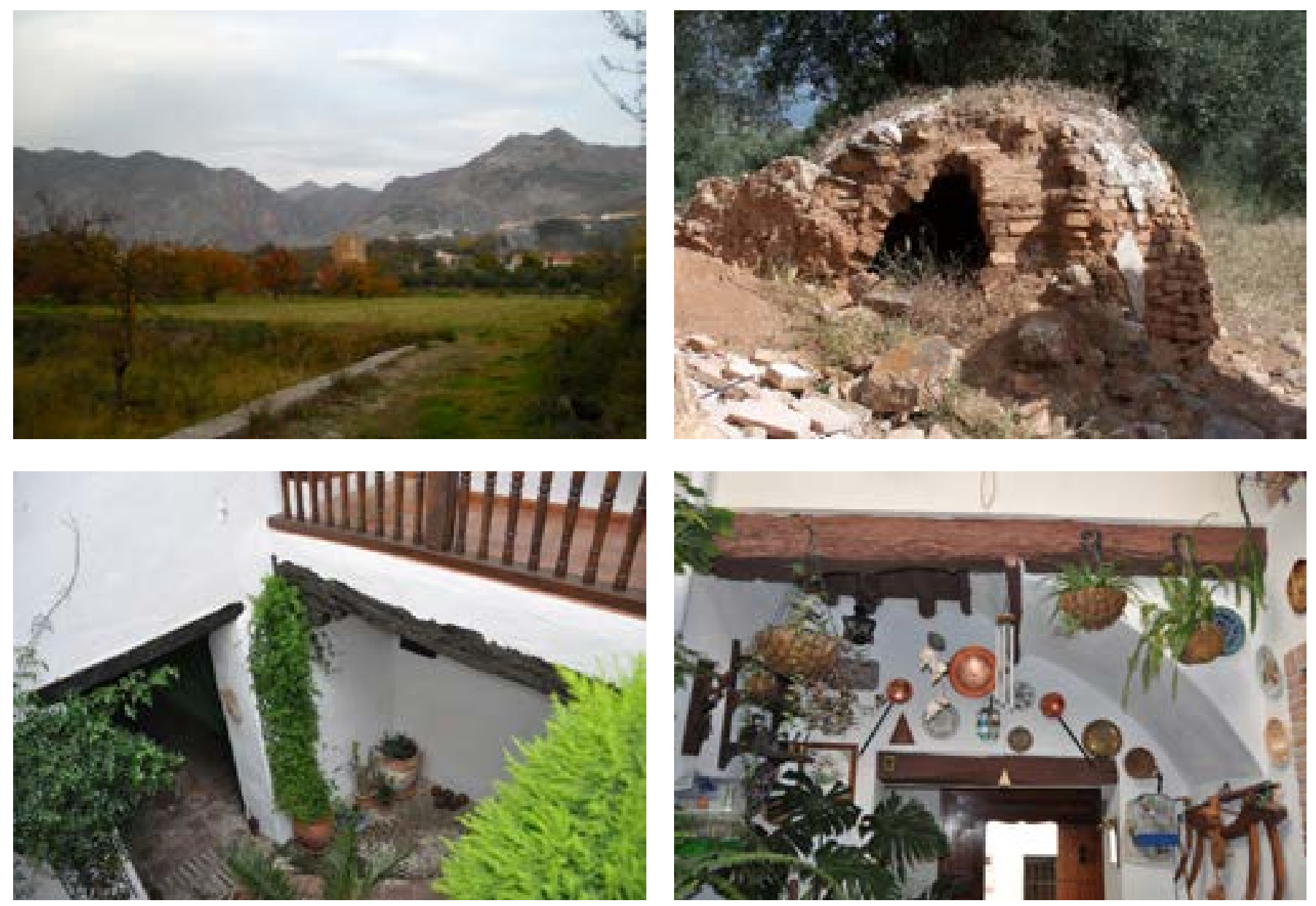

Márgena fue uno de los barrios andalusíes más importantes de la alquería de Dúrcal. Durante el Repartimiento del lugar (1572) se aprecia que los nuevos colonos consideraron el lugar poco atractivo y se refiere su progresivo deterioro. Actualmente es la principal vega de este pueblo

Tras ser consagrada como iglesia -cuando se construyó el nuevo templo sobre algunos de los cementerios del pueblo- se abandonó llegando a nuestros días como parte de una vivienda particular (MOLINA, 2012: 333-343;

Ruinas de un antiguo horno de pan situado en el despoblado de Tablate

Vista del patio de la vivienda de la Calle Real $n .^{0} 7$ de Acequias. En ella se puede observar la única galería que conversa este ámbito

Vista de la galería sur-este de la casa de Maruja ubicada en la Calle Llana de Saleres. En ella se aprecia el cuerpo de la escalera tabicada primitiva hoy desmantelada y sustituida por una moderna que ha invadido la galería noroeste de la vivienda MOLINA, 2013: 13-22; ESPINAR, PADILLA, 2009: 71-94). El devenir de las necrópolis musulmanas fue similar: la mayor parte de ellas se desmantelaron y usaron bien como solares, huertos o corrales; empleándose sus lápidas como material de acarreo para alzar nuevas estructuras.

Otro hito destacado presente en algunos lugares fueron las fortalezas urbanas o torres de alquería que guarecían y organizaban el poblamiento de ciertos barrios. En el valle de Lecrín contamos con tres ejemplos: la torre del Tío Vayo situada en el barrio alto de Albuñuelas, la torre de Restábal que controlaba el paso del camino real que desde allí transitaba a la costa y el fuerte de Márgena en Dúrcal. Eran fábricas de planta cuadrada o rectangular, con varios pisos de altura, aljibe en su parte baja y una muralla aledaña. Tras la conquista estas tres fortificaciones se adoptaron como viviendas y su cerca 
se usó como corral o muro para adosar otras viviendas (MOLINA FAJARDO, 2013: 645-654; PEDREGOSA, 2011: 293-302).

El barrio acogía además las viviendas de los lugareños. La documentación y arquitecturas aún presentes en la comarca muestran casas construidas con materiales propios del medio: alzados en tapial, mampostería y ladrillo; uso de madera, cañizo y teja para su cubrición, etc. ${ }^{15}$ Las moradas se agrupaban formando manzanas, muchas veces distribuidas en adarves y presentando una superposición espacial entre las distintas casas vecinas, fruto de las numerosas divisiones que han sufrido los solares a lo largo del tiempo. El uso de la algorfa también fue frecuente. Sus fachadas tenían pocos vanos y puertas, careciendo asimismo, de infraestructuras para su abastecimiento hídrico que se realizaba acarreando recipientes desde los aljibes o acequias hasta las residencias. La superficie de las viviendas durante el siglo XVI fue muy variable, solían contar con al menos dos plantas de altura y a veces incluían en su perímetro algunos metros de plazoleta o calleja colindante. También fue usual la presencia de huertos aparejados a las casas para su servicio $^{16}$. La vida cotidiana de los vecinos del valle de Lecrín no se restringió únicamente al núcleo urbano sino que se extendía por las inmediaciones de los barrios. En estos bordes se hallaban las tierras de cultivo de propiedad individual -conocidas como tierras mamluka- y dedicadas al regadío (TRILLO, 2006: 234). En esa vida campesina los edificios destinados a la molienda tendrán gran importancia productiva y social. El valle de Lecrín en época nazarí y católica contó con almazaras y molinos de grano, parte de ellos hidráulicos y otros tantos de tracción animal ${ }^{17}$. La mayor parte de ellos fueron propiedades privadas en manos de molineros moriscos y tras la expulsión pasaron a la Corona. Los libros de apeo describen como estas construcciones sufrieron destrozos tras la insurrección de las Alpujarras y cómo su puesta en marcha fue principal para afianzar la nueva población ${ }^{18}$. En las cercanías de los pueblos también existieron áreas con albercas destinadas a la cocción de vegetales como el lino o el esparto. Un paraje importante de albercas y molinos se sitúo por ejemplo en Acequias, a la entrada del pueblo desde el camino de Nigüelas.

En relación con la vida agrícola también existieron sencillas cabañas, chozas, cortijuelos y alcatifas que darían reguardo durante los quehaceres diarios del campo y acogerían ciertas industrias de transformación (MOLINA FAJARDO, 2012: 707-762). Por su parte, algunos pueblos como Albuñuelas, contaron con un número destacado de cortijadas (su Libro de población enumera 15) alejadas de las alquerías y destinados a la explotación de propiedades extensas de secano (MOLINA FAJARDO, 2012: 685-697).

Finalmente me gustaría señalar la importancia de los hușūn o castillos medievales como hitos organizadores del poblamiento del valle de Lecrín. La comarca -quizás debido a su posición estratégica- contó con un nutrido
15

Más información sobre los materiales y las técnicas constructivas en el valle del Lecrín durante la Edad Moderna en MOLINA FAJARDO, 2012: 226-251.

16

Más información sobre la arquitectura doméstica comarcal en MOLINA FAJARDO, 2012: 205-460; 2015: 487-517.

17

En el Libro de población de Acequias por ejemplo se dice que existían dos almazaras, una hidráulica y otra movida por una bestia: "Ay el dicho lugar dos molinos de aceyte el uno de agua y el otro de viga que se trae con vestias, estan tanbien caydos e perdidos heran de moriscos alçados e perteneçen a su magestad" (AHPGr, Libros de Población del Reino de Granada-6393, fols. 15v, 16r.).

18

En las condiciones para la población de Acequias se cita: "Los molinos de pan e azeite se les da para que gozen dellos por tiempo de seis años primeros siguientes con que an de ser obligados a los rreparos e rredificar a costa de todos los pobladores o de dallos y en cargallos a uno u dos o mas de lo de los mismos para que lo hagan por lo que se conçertare con ellos e los que ansi los hiziere gozen de la rrenta de los dichos molinos y el dicho tiempo con que an de lleuar la maquila como se lleuare la caueça del partido de donde fueren los cules les ande dexar al fin de lo dicho tiempo moliente e corientes con todo lo necesario para ello" (AHPGr, Libros de Población del Reino de Granada-6393, fols. 12v, 13r.). 


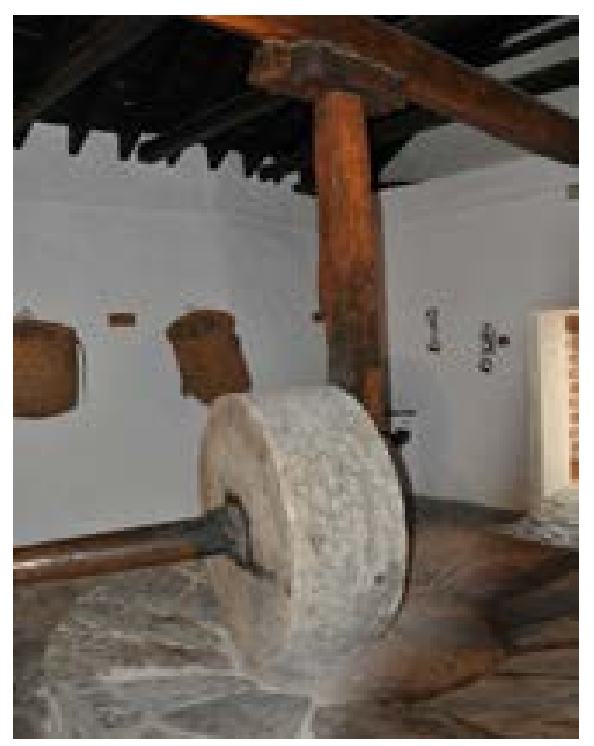

Sala de molienda en la almazara de las Laerillas (Nigüelas) que funcionaba con fuerza animal. Esta parte del molino parece ser la más primitiva del complejo que cuenta también con un importante molino hidráulico

19

Me refiero al castillo de Lojuela (Murchas), el peñón de los Moros de Dúrcal, el castillejo de Restábal, el castillo de Mondújar, el de Lanjarón, el yacimiento del Mojinar de Chite y las desaparecidas ruinas de las Paredes de los Moros de Albuñuelas. No obstante, es posible que la comarca contara con alguna otra fortificación pues las fuentes, así como uno de los sitiales de coro de la catedral de Toledo, recogen la existencia de un castillo en la alquería de Padul y es posible que existiera otro tipo de defensa en Nigüelas (MOLINA FAJARDO, 2012: 881-989; 511-570).

20

Un ejemplo de ese abandono y pérdida de valor defensivo y jurisdiccional lo encontramos en Restábal cuando en su Repartimiento se entrega el castillo como parte de una tierra de secano: "Mas en el Pago que diçen del Castillo el Castillo y una haça que esta en medio y una ladera debajo de tierra de secano linda con el dicho Castillo y una haça de tierra de secano del maestro Martínez y con las Peñas" (ESPINAR MORENO et ál., 2006: 365).

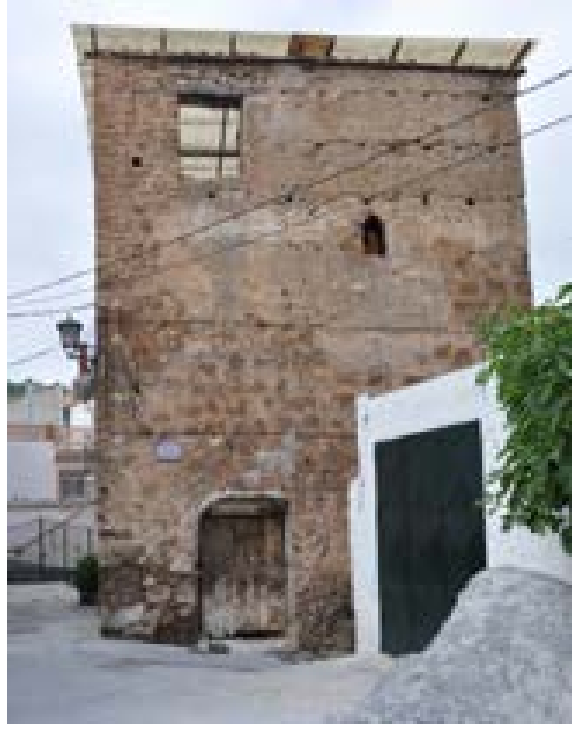

Torre del Tío Vayo, ubicada en el antiguo barrio de Najo de Albuñuelas

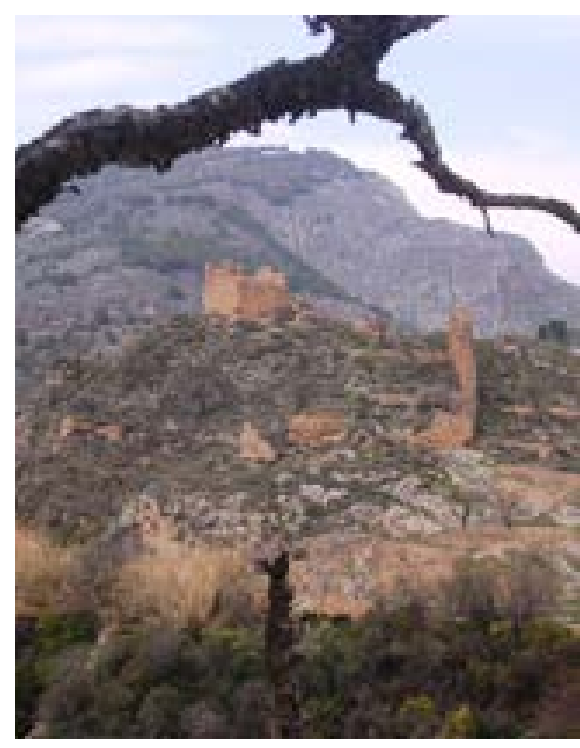

Vista del castillo de Lojuela, hoy término de Murchas | fotos María Aurora Molina Fajardo aparato defensivo en el que se disponían al menos siete castillos ${ }^{19}$. Estas construcciones se ubicaron en lugares escarpados a cierta distancia de las alquerías a las que darían salvaguarda, controlando los principales caminos que por allí transitaban así como los cauces fluviales. Tras la conquista castellana estos espacios vivieron una suerte muy desigual, destruyéndose y abandonándose casi todos ${ }^{20}$ a excepción de los de Mondújar y Lanjarón. Ambos quedaron en manos de un alcaide nombrado por la Corona, siendo aderezados y mejorados como puntos fuertes del territorio (MOLINA FAJARDO, 2012: 934-966). 


\section{BIBLIOGRAFÍA}

- ESPINAR MORENO, M. et ál. (2006) El Valle. Libros de Apeo y Repartimiento de Melegís y Restábal. Lecrín: Excmo. Ayuntamiento de El Valle, 2006

- ESPINAR MORENO, M. (2009) Habices de la mezquita y rábitas de Cozvíjar en 1502. Miscelánea medieval murciana, 2009, n. ${ }^{\circ} 33$, pp. 33-54

- ESPINAR MORENO, M.; PADILLA MELLADO, L. L. (2009) Nigüelas, una alquería musulmana del Valle de Lecrín: la mezquita y otros centros religiosos. En ESPINAR MORENO, M.; GARCÍA GUZMAN, M. M. (coord.) La ciudad Medieval y su territorio. Cádiz: Agrija Ediciones, 2009, pp. 71-94

- FERRER, M. (1994) Libro y demás instrumentos de la población del Lugar del Padul del Partido del Valle de Lecrín. Año de 1571. Padul: Ayuntamiento de Padul, 1994

- FERRER, M. (2001) Libro de Apeo y Repartimiento de Suertes del lugar de Lanjarón. Lanjarón: Ayuntamiento de Lanjarón, 2001

- FERRER, M. (2003) Libro de Apeo y Repartimiento de Suertes de Las Albuñuelas. Granada: Ayuntamiento de Albuñuelas, 2003

- GARCÍA DEL MORAL GARRIDO, M. T. (2010) Nueva contribución al estudio de los nombres del lugar del Mediodía Hispánico: el municipio de Lecrín (Acequias, Béznar, Chite, Mondújar, Murchas y Talará), de la comarca del Valle de Lecrín (Granada). Tesis doctoral inédita, Universidad de Sevilla, 2010

- GARcía GRANADOS, J. A. et ál. (1983) Las termas romanas de Lecrín (Granada). Avance de la $1^{\text {a }}$ campaña. XVII Congreso Nacional de Arqueología: Logroño, 1983. Zaragoza: Secretaria General de los Congresos Arqueológicos Nacionales, 1985, pp. 897902

- GARCÍA PÉREZ, J. F. (2015) Paisajes históricos del área norte del Valle de Lecrín: de la época nazarí a la conquista castellana. Tesis doctoral inédita. Universidad de Granada, 2015

- MOlinA FAJARDo, M. A. (2012) El espacio rural granadino tras la conquista castellana: urbanismo y arquitectura con funciones residenciales del Valle de Lecrín en el siglo XVI. Tesis doctoral inédita, Universidad de Granada, 2012

- MOLINA FAJARDO, M. A. (2013) Readaptación doméstica de ciertas estructuras defensivas tras la expulsión de los moriscos: las torres de alquería del Valle de Lecrín (Granada). Actas del XII Simposio Internacional de Mudejarismo. Teruel 14-16 de
Septiembre. Teruel: Centro de Estudios Mudéjares, 2013, pp. 645-654

- MOLINA FAJARDo, M. A. (2015) Habitando la alquería: aproximación a la vivienda rural granadina tras la conquista del Reino. En DÍEZ JORGE, E.; NAVARRO PALAZÓN, J. (ed.) La Casa Medieval En La Península Ibérica. Madrid: Sílex, 2015, pp. 487517

- MOLINA FAJARDO, M. A. (2017) Territorial organisation, irrigation and religious space in the Islamic Kingdom of Granada. The case of the village of Acequias. Das Mittelalter. Beihefte, 2017, n. ${ }^{\circ} 4$, pp. 266-275

- PEDREgosA MEgíAS, R. J. (2011) La Torre de Márgena o Marchena Dúrcal (Granada): una torre de alquería y su albacar. Antiquitas, 2011, n. 23 , pp. 293-302

- RAMOS MILLÁN, A.; OSUNA VARGAS, M. M. (2001) La gestión del impacto arqueológico en carreteras. Un ejemplo andaluz en la Autovía Alhendín-Dúrcal (Granada). Granada: Arkaîon, 2001

- TORO MOYANO, I.; ALMOHALLA GALLEGO, M. (1979) Industrias del paleolitico superior en la provincia de Granada. Cuadernos de Prehistoria y Arqueología de la Universidad de Granada, n. ${ }^{\circ} 4$, 1979, pp. 1-20

- TRILLO SAN JOSÉ, C. (2006) La organización del espacio de la alquería en la frontera nororiental del reino de Granada. Studia Historica, Historia Medieval, n. ${ }^{\circ} 24,2006$, pp. $227-240$ 